\title{
Sub-Chronic Effects of $s$-Limonene on Brain Neurotransmitter Levels and Behavior of Rats
}

\author{
Wenjun ZHou, Miyuki YoshioKA and Hidehiko YoKogoshi* \\ Laboratory of Nutritional Biochemistry, Global COE Program in the 21st Century, \\ Graduate School of Nutritional and Environmental Sciences, The University of Shizuoka, Yada, \\ Suruga, Shizuoka 422-8526, Japan
}

(Received November 27, 2008)

\begin{abstract}
Summary The present study was designed to gain insight into the effects of $s$-limonene on the brain after 1-wk administration. For this purpose, neurotransmitters such as dopamine (DA), serotonin (5-HT), $\gamma$-aminobutyric acid (GABA), glutamic acid (Glu) and some of their metabolites (DOPAC and 5-HIAA) were determined by HPLC-ECD and amino acid analyzer after 1 -wk administration of $s$-limonene of different concentrations $(0,5,25,50 \mathrm{mg}$ / $\mathrm{kg}$ ). Significant changes, such as GABA, 5-hydroxyindoleacetic acid (5-HIAA) and 5-HT, were confirmed. At the same time, basal hypothalamic-pituitary-adrenal (HPA) activity after 1-wk administration of s-limonene was evaluated by corticosterone. Considering the increment of GABA and the changes of other neurotransmitters, anti-stress effects after 1wk administration were observed. The experimental results showed that $s$-limonene could inhibit HPA activity under physical stress and this anti-stress effect of $s$-limonene may act through the $\mathrm{GABA}_{\mathrm{A}}$ receptor.
\end{abstract}

Key Words s-limonene, anti-stress effects, GABA, 5-HT, foot shock

$s$-Limonene is a component of lemon essential oil. It has been reported that acute administration of $s$ limonene at high concentration can relieve physical and psychological stress (1). There are other reports about its acute functions in modifying monoamine levels in rat brains and brain waves from human tests (2). In addition, some researchers have also demonstrated by the microdialysis method that lemon essential oil components could stimulate the release of acetylcholine when rats were facing persistent painful stimulation (3). From these reports, we thought that s-limonene showed potential to be used as a medical additive or substitute therapy in the pharmaceutical field for helping people troubled by stress. However, it is unknown what happens in the brain after chronic or sub-chronic administration of $s$-limonene.

In this study, the effects of 1-wk administration of $s$ limonene on neurotransmitters were determined, and the possible anti-stress effects were evaluated. The possible relationship between neurotransmitter changes and anti-stress effects was also explored.

\section{MATERIALS AND METHODS}

Animals. Wistar male rats (200-250 g) (Japan SLC,

\footnotetext{
${ }^{*}$ To whom correspondence should be addressed.

E-mail: yokogosi@u-shizuoka-ken.ac.jp

Abbreviations: ACTH, adrenocorticotropic hormone; BZP, benzodiazepine; $\mathrm{CRH}$, corticotrophin-releasing factor; DA, dopamine; DMSO, dimethyl sulfoxide; DOPAC, dihydroxyphenylacetic acid; GABA, $\gamma$-aminobutyric acid; Glu, glutamic acid; 5-HIAA, 5-hydroxyindoleacetic acid; HPA, hypothalamic-pituitary-adrenal; 5-HT, serotonin.
}

Inc., Shizuoka, Japan) were individually housed at $23 \pm 1{ }^{\circ} \mathrm{C}$ in a room with a 12-h light-dark cycle. Rats were given a commercial diet (stock diet: CE-2, CLEA Japan, Inc., Tokyo, Japan). Foodstuff and water were freely available. Rats in each group were only used once with one purpose. The experimental procedures were in accordance with the guidelines of the University of Shizuoka for the Care and Use of Laboratory Animals, based on those of the American Association for Laboratory Animal Science.

Dose-dependent changes of neurotransmitters induced by 1-wk administration of s-limonene. Seventy-two rats were split randomly into 4 groups (18 rats per group), with similar body weights among the groups. The rats were orally administered corn oil ( $1 \mathrm{~mL} / \mathrm{kg}$, vehicle) or s-limonene dissolved in corn oil $(5,25$, or $50 \mathrm{mg} / \mathrm{kg})$ according to their group once a day from 10:00 am to 12:00 pm. After 1-wk administration, the rats were decapitated, and the brains were removed immediately and dissected to obtain hypothalamus and amygdala regions quickly on an ice-cold operation table. Serum was also collected to estimate basal HPA activity. Brain regions and serum were stored at $-80^{\circ} \mathrm{C}$ until analyzed.

Stress-exposure analysis by foot-shock. A foot-shock device was used to give physiological stress $(5 \mathrm{~mA}$ electric shock lasted for $5 \mathrm{~s}$ with $25 \mathrm{~s}$ interval, continued for $30 \mathrm{~min})$. Rats were split into four groups. Rats in the Vehicle/no-Stress and Vehicle/Stress groups were administered corn oil for $1 \mathrm{wk}$. For those in the $s$-Limonene/ Stress group, $50 \mathrm{mg} / \mathrm{kg} s$-limonene was administered for $1 \mathrm{wk}$. In order to examine the function of GABA receptor, rats in the $s$-Lim \& Flu/Stress group were orally administered $50 \mathrm{mg} / \mathrm{kg} \mathrm{s}$-limonene for $1 \mathrm{wk}$ and $1 \mathrm{mg} /$ 
Table 1. Concentrations of Glu and GABA in brain.

\begin{tabular}{lcccc}
\hline \multicolumn{1}{c}{ Amino acids } & Vehicle & $\begin{array}{c}s \text {-Limonene } \\
(5 \mathrm{mg} / \mathrm{kg})\end{array}$ & $\begin{array}{c}s \text {-Limonene } \\
(25 \mathrm{mg} / \mathrm{kg})\end{array}$ & $\begin{array}{c}s \text {-Limonene } \\
(50 \mathrm{mg} / \mathrm{kg})\end{array}$ \\
\hline Glu $(\mu \mathrm{mol} / \mathrm{mL})$ & $3.06 \pm 0.05$ & $3.02 \pm 0.03$ & $2.92 \pm 0.02^{\#}$ & $2.91 \pm 0.02^{*}$ \\
GABA $(\mu \mathrm{mol} / \mathrm{mL})$ & $0.61 \pm 0.01$ & $0.621 \pm 0.01$ & $0.65 \pm 0.01^{\#}$ & $0.66 \pm 0.02^{\#}$ \\
\hline
\end{tabular}

Values are the mean \pm SE for 18 rats per group. Group: Vehicle (corn oil $1 \mathrm{~mL} / \mathrm{kg}$ ) group, $s$-limonene $(5,25,50 \mathrm{mg} / \mathrm{kg}$ ) groups, $p<0.05$ was considered significant. ${ }^{*} p<0.01,{ }^{\#} p<0.05$.

kg flumazenil (Sigma, $>99 \%$ ), a type of $\mathrm{GABA}_{\mathrm{A}}$ receptor benzodiazepine (BZP) site antagonist, was also administered orally $30 \mathrm{~min}$ before being exposed to physiological stress. Flumazenil was dissolved in dimethyl sulfoxide (DMSO). For the other three groups, DMSO was given $30 \mathrm{~min}$ before the experiment.

At the end of the anti-stress tests, the rats were decapitated immediately, and the serum was collected into tubes. Brains were dissected immediately and stored at $-80^{\circ} \mathrm{C}$.

Chemical analysis. DA, 5-HT and their metabolites were determined by the method described previously (4). Briefly, brain samples from different brain regions were homogenized at $4^{\circ} \mathrm{C}$ in $2 \mathrm{M}$ perchloric acid (PCA) solution using an ultrasonic cell disruptor (Branson Sonifier, SC Co., Tokyo). The homogenate was left to stand for $1 \mathrm{~h}$ at $4^{\circ} \mathrm{C}$ and then centrifuged at 15,000 rpm for $15 \mathrm{~min}$. The supernatant $(200 \mu \mathrm{L})$ was collected and mixed with $40 \mu \mathrm{L} 1 \mathrm{M}$ sodium acetate (NaAc). The mixture was filtrated $(0.45 \mu \mathrm{m}$ Cellulous Acetate filter, ADVANTEC) into a new Eppendorf tube for HPLC analysis. Monoamines were determined with the HPLC system under the following conditions: column temperature, $25^{\circ} \mathrm{C}$ (Eicom, ECD-300; Eicom Packed Column: SC-5ODS, $3.0 \phi \times 150 \mathrm{~mm}$ ); the mobile phase was composed of $0.05 \mathrm{M} \mathrm{NaAc}, 0.05 \mathrm{M}$ citric acid, $15 \%$ methanol, $160 \mathrm{mg} / \mathrm{L}$ 1-octanesulfonic acid sodium salt and $5 \mathrm{mg} / \mathrm{L}$ EDTA·2Na. Chromatograms and all calculations were recorded using an integrator (Borwin: Nihonbunkoh, Tokyo, Japan).

The concentrations of free amino acids in the brain such as Glu and GABA were determined by an automatic amino acid analyzer (JEOL, JLC-500/V). Brains were homogenized at $4^{\circ} \mathrm{C}$ in $3 \% 5$-sulfosalicylic acid (SSA) (Wako, $\geq 99 \%$ ) aqueous solution and the supernatant was used for amino acid analysis.

Corticosterone in serum was determined using a similar HPLC-UV method reported previously (5).

Statistical analysis. All data were analyzed using SPSS 11.0. For neurotransmitter or corticosterone analysis, the independent $t$-test and one-way ANOVA were used to check the dosage effects with the StudentNewman-Keuls post hoc test. Data are expressed as the means \pm SE and differences were considered significant at $p<0.05$.

\section{RESULTS}

Dose-dependent changes of neurotransmitters induced by 1wk administration of s-limonene

The contents of Glu and GABA, which are important neurotransmitters in the whole brain, were determined (Table 1). It seems that the 1-wk administration of $s$ limonene $(25$ and $50 \mathrm{mg} / \mathrm{kg}$ ) significantly decreased the concentration of Glu in the brain. On the other hand, GABA concentration in the whole brain increased in a dose-dependent manner.

The concentration of monoamines such as DA, 5-HT and their metabolite ratios (5-HIAA/5-HT and DOPAC/ DA) in the hypothalamus and amygdala are shown in Fig. 1. There was no significant difference in DA (Fig. 1D), DOPAC/DA (Fig. 1D) or 5-HT (Fig. 1C) in the amygdala; however, the ratio of 5-HIAA/5-HT (Fig. 1C) in the amygdala increased significantly with the administration of s-limonene. In the hypothalamus, the 1-wk administration of s-limonene also failed to induce a significant change of DA (Fig. 1B). However, the metabolism ratio of 5-HIAA/5-HT (Fig. 1A) and DOPAC/DA (Fig. 1B) increased significantly because of the administration of s-limonene with a dosage of $50 \mathrm{mg} / \mathrm{kg}$. In addition, 5-HT concentration (Fig. 1A) decreased significantly with the administration of $s$-limonene.

The serum concentration of corticosterone in the slimonene-administered group was almost the same as that of the vehicle group. It seems that the basal HPA activities were almost identical. In addition, the body weight and food intake between these two groups were also similar (data not shown).

Stress-exposure analysis by foot-shock

Foot shock stress is considered a very useful stimulus for providing a stressful environment. In our previous report (1), this foot shock model was used to evaluate the anti-stress effect of food components. In this study, the same shock conditions were used. In Fig. 3, the serum concentration of corticosterone in the Vehicle/ Stress group was increased significantly compared with the Vehicle/no-Stress group. However, the pre-administration of $s$-limonene attenuated the enhanced release of corticosterone significantly, but not to the Vehicle/ no-Stress level.

It has been demonstrated that GABA and its receptors are effective constituents for relieving stress $(6,7)$; therefore, in this study, a $\mathrm{GABA}_{\mathrm{A}}$ receptor BZP site antagonist, flumazenil, was used to examine whether $s$ limonene's anti-stress effect could be attributed to the changes in GABA and its receptors. The results showed that the pre-administration of flumazenil antagonized the anti-stress effects induced by $s$-limonene.

The changes in monoamines are shown in Fig. 4. It was shown that the concentration of 5-HT in the hypothalamus (Fig. 4A) and amygdala (Fig. 4C) were 

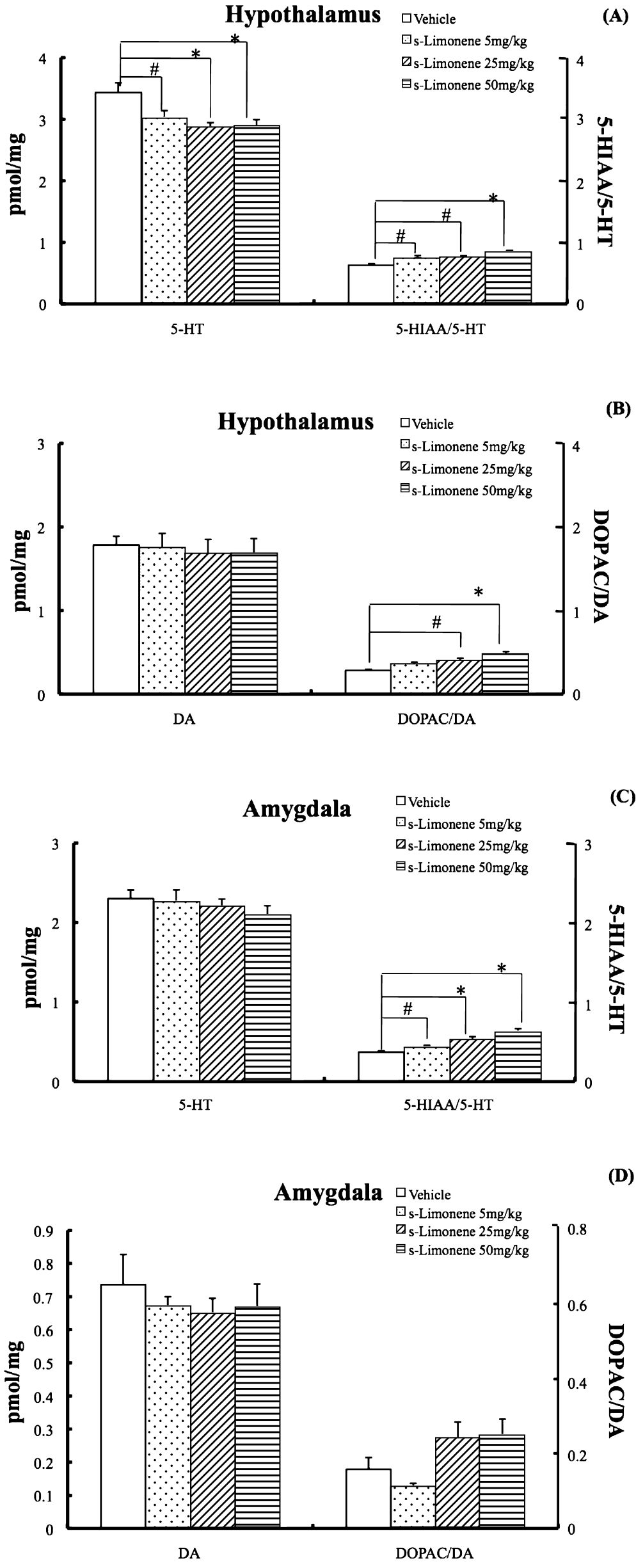

(A)

(B)

(C)

(D)

Fig. 1. Monoamines and their metabolites in hypothalamus and amygdala after 1-wk administration of $s$-limonene. Values are the mean \pm SE for 18 rats per group. Group: Vehicle (corn oil $1 \mathrm{~mL} / \mathrm{kg}$ ) group, s-limonene $(5$, $25,50 \mathrm{mg} / \mathrm{kg}$ ) groups, $p<0.05$ was considered significant. ${ }^{*} p<0.01,{ }^{*} p<0.05$. 
increased by exposure to foot-shock stress; however, if $s$ limonene was given before the stress, 5-HT concentration decreased significantly. Meanwhile this effect on the 5-HT level was reversed by the administration of flumazenil, while the metabolite rates of 5-HIAA/5-HT increased significantly with the administration of $s$ limonene. Usage of flumazenil did not alter the change of metabolite ratio induced by s-limonene. Meanwhile, although foot shock induced an increase of DA concentration in hypothalamus and amygdala regions (Fig. 4B and D), the administration of $s$-limonene changed this trend very little. Nor did flumazenil alter the concentration of DA. Except that $s$-limonene changed the ratio of DOPAC/DA, there is no change of DOPAC/DA with the treatments. The foot-shock stress decreased the norepinephrine (NE) contents significantly, which is in accordance with an other's report (data not shown) (8). However the administration of $s$-limonene and flumazenil did not alter the changes induced by stress.

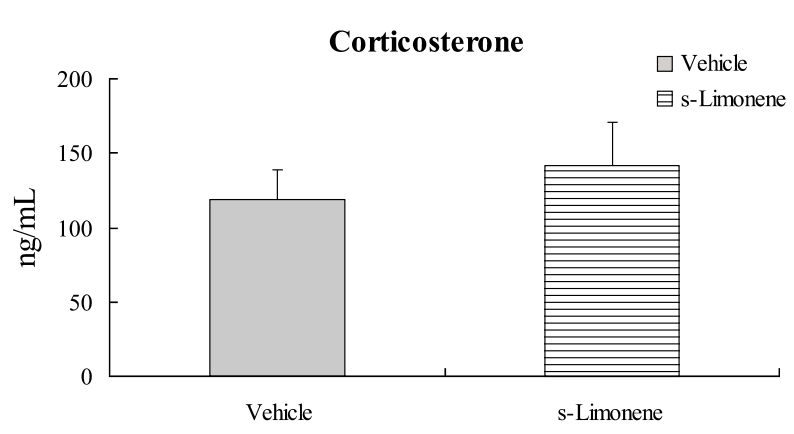

Fig. 2. Corticosterone concentration in serum of rats. Values are the mean \pm SE for 18 rats per group. Group: Vehicle (corn oil $1 \mathrm{~mL} / \mathrm{kg}$ ) group, s-limonene $(5,25$, $50 \mathrm{mg} / \mathrm{kg}$ ) groups, $p<0.05$ was considered significant. ${ }^{*} p<0.01,{ }^{\#} p<0.05$.

\section{DISCUSSION}

Essential oils, such as lavender oil, lemon essential oil and grapefruit oil extracted from plants, have been used widely in many fields. Many functions have been reported such as anti-stress effects (9), an anti-allergy effect (10) or modulation of the sympathetic nerve system $(11,12)$. However, most functional reports on these oils were based on olfaction; that is, these reported functions may act mainly through olfaction. However, these odor components in oils are contained in vegetables or fruits which are eaten as foods. Therefore, the functions of essential oils, absorbed through the gastrointestinal tract, on the brain should be explored. In our previous study, the oral administration of $s$-limonene relieved physical and psychological stress (1). In that study, only an acute effect (rats were administrated lemon essential oil once) was examined, but the mechanism of how $s$-limonene could relieve stress is still unknown. The changes in neurotransmitters in the brain induced by s-limonene, which was administrated orally, have not been reported; therefore, in this study, the changes of monoamines in the brain were determined.

According to reports $(13,14)$, both GABA and Glu could influence HPA axis activity. Here, although GABA concentration increased and Glu concentration declined with the usage of s-limonene, those phenomena did not change corticosterone contents. The animal activity amounts did not vary a lot between groups (data not shown). Therefore, the observed anti-stress effects in the next experiments could not be attributed to sedation.

Usually, stress activates the HPA axis, and corticosterone is secreted from the adrenal glands to the blood. Electric shock induced the increase of the serum corticosterone concentration. It is also known that the changes in DA, 5-HT, NE and their metabolites in the

\section{Corticosterone}

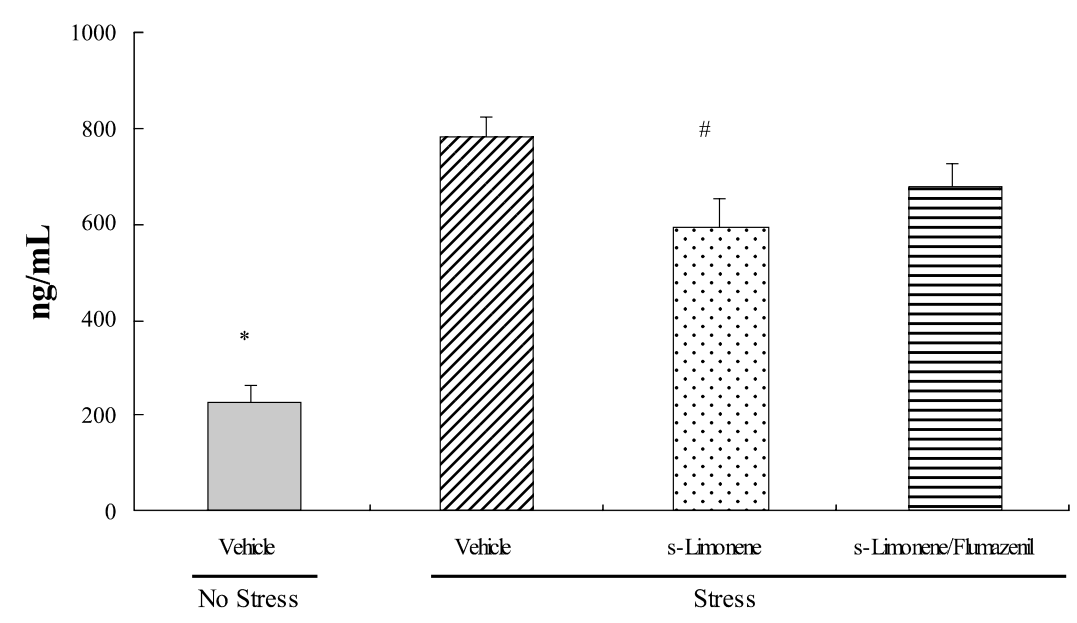

Fig. 3. Corticosterone concentration in serum of rats after foot shock stress. Values are the mean \pm SE. Group: Vehicle/noStress (corn oil $1 \mathrm{~mL} / \mathrm{kg}$ ) group, Vehicle/Stress (corn oil $1 \mathrm{~mL} / \mathrm{kg}$ ) group, s-Limonene/Stress (s-limonene: $50 \mathrm{mg} / \mathrm{kg}$ ) group, s-Limonene \& Flumazenil/Stress ( $s$-limonene: $50 \mathrm{mg} / \mathrm{kg}$, flumazenil: $1 \mathrm{mg} / \mathrm{kg}$ ) group. Foot-shock condition: $5 \mathrm{~mA}$ lasting 5 s, 25 s interval, $30 \mathrm{~min} ; p<0.05$ was considered significant. ${ }^{*} p<0.01,{ }^{*} p<0.05$. 


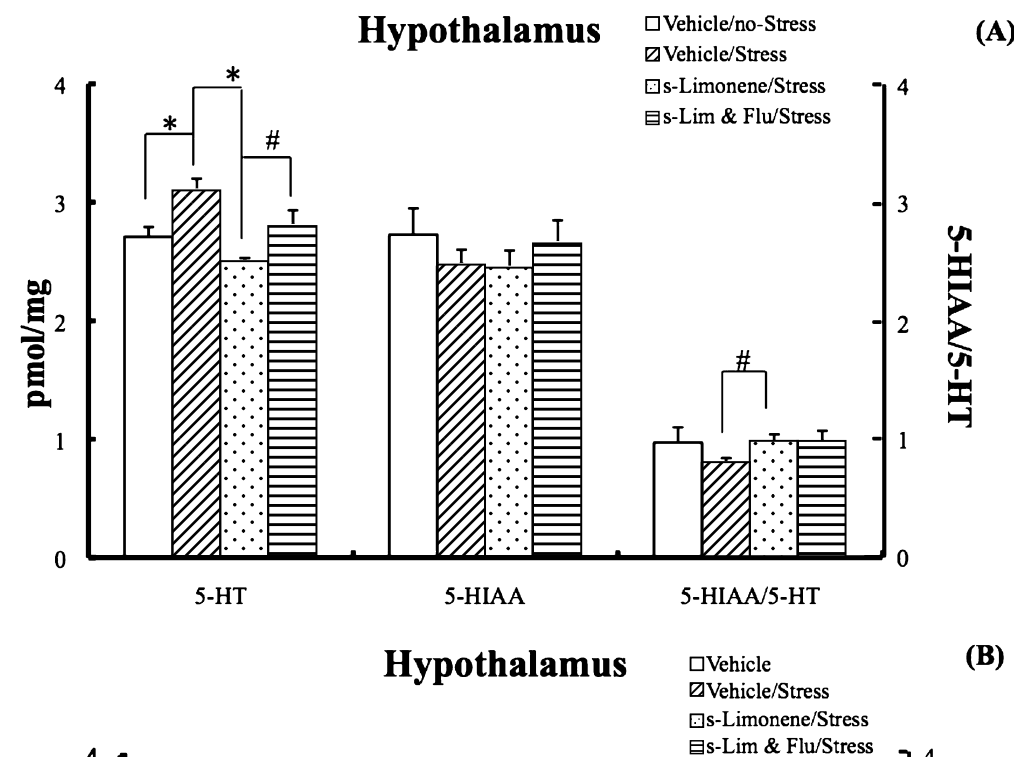

(A)

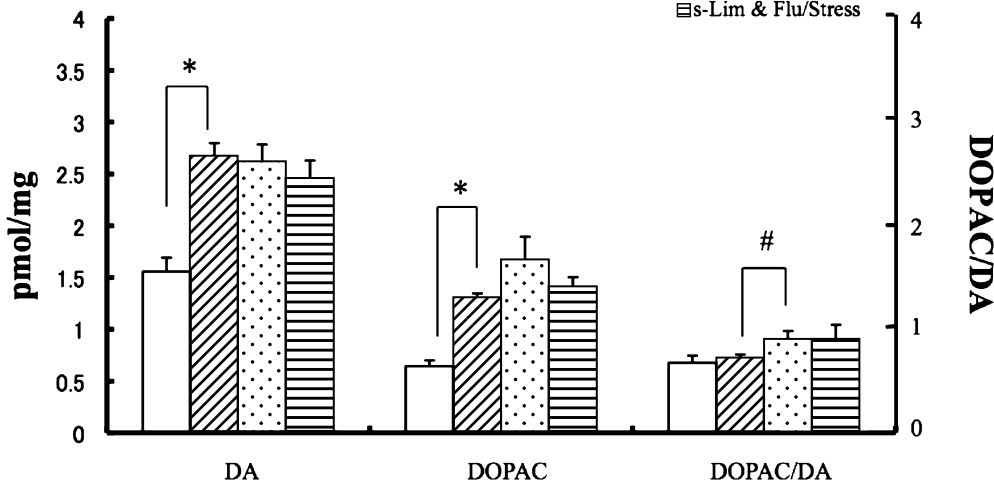

B)

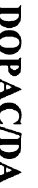

Amygdala $\square$ Vehicle/no-Stress

(C)

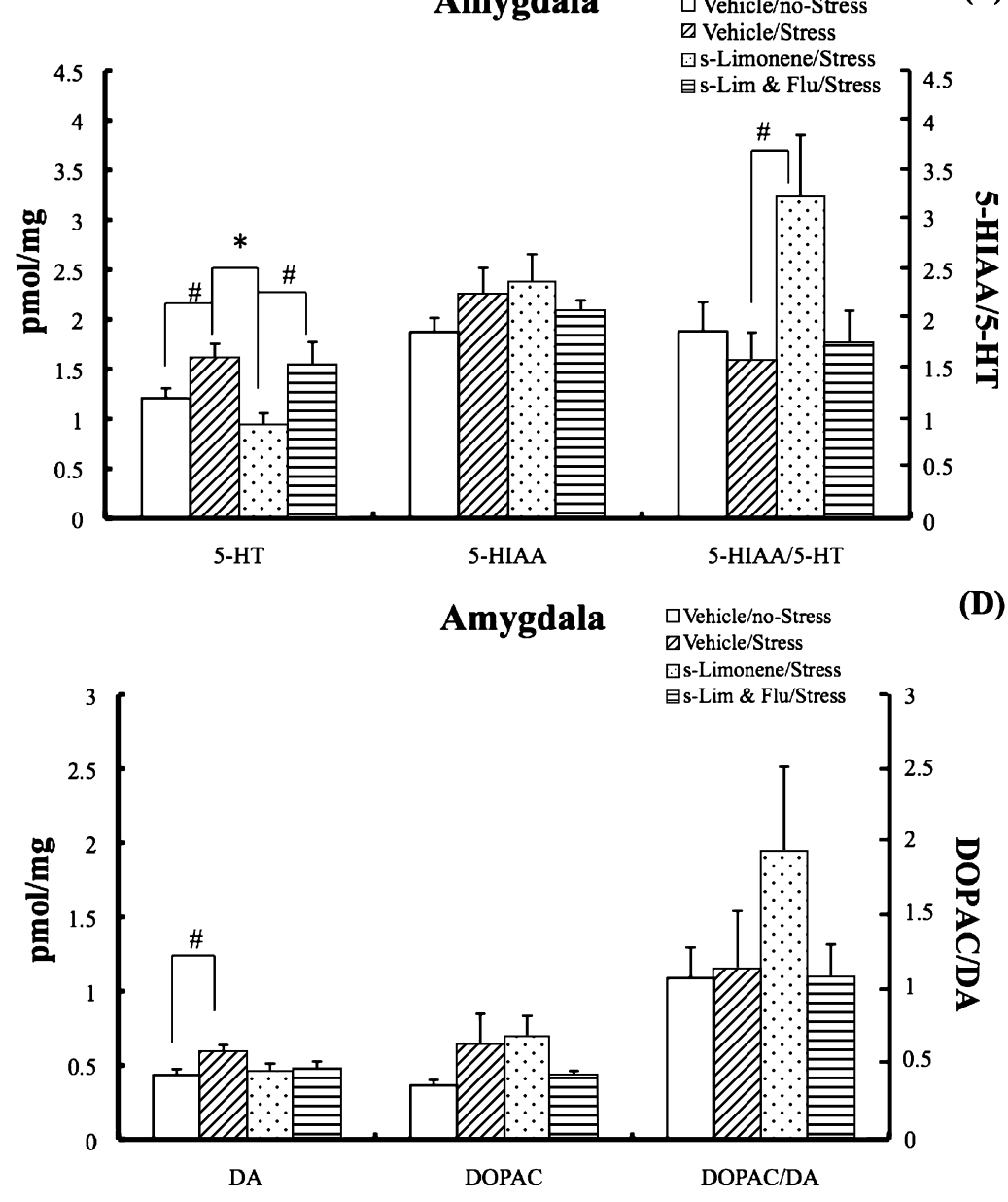

Fig. 4. Concentration of 5-HT and its metabolism rate in hypothalamus and amygdala after foot shock. Values are the mean \pm SE Group: Vehicle/noStress (corn oil $1 \mathrm{~mL} / \mathrm{kg}$ ) group, Vehicle/Stress (corn oil $1 \mathrm{~mL} / \mathrm{kg}$ ) group, sLimonene/Stress ( $s$-limonene: $50 \mathrm{mg} /$ $\mathrm{kg})$ group, s-Limonene \& Flumazenil/ Stress ( $s$-limonene: $50 \mathrm{mg} / \mathrm{kg}$, flumazenil: $1 \mathrm{mg} / \mathrm{kg}$ ) group. Foot-shock conditions: $5 \mathrm{~mA}$ lasting $5 \mathrm{~s}, 25 \mathrm{~s}$ interval, 30 min; $p<0.05$ was considered significant. ${ }^{*} p<0.01,{ }^{\#} p<0.05$. 
brain induced by various stressors are stressor-dependant (15). For example, the ratio of 5-HIAA/5-HT was very different with the change of stressor when rats were exposed under restraint stress, foot-shock stress or other stress (15). The same phenomena were observed for DA. It has been reported that electric shock would increase 5 -HT synthesis $(15,16)$; our results were in accordance with these reports. With foot-shock stress, both the corticosterone concentration in serum and 5HT concentration in the brain were increased; however, this tendency was partially reversed by the administration of $s$-limonene. It was also found that under serious foot shock conditions, the DA concentration in the hypothalamus would increase significantly (17).

The main components of the stress system are the hypothalamic-pituitary-adrenal (HPA) loop and the locus ceruleus-norepinephrine/autonomic pathways. Under acute stress conditions, stressors result in $\mathrm{CRH}$ release from paraventricular neurons in the hypothalamus, and then activate ACTH release from the pituitary. Corticosterone release was controlled by ACTH. GABA, as a very important neurotransmitter in the brain, induces hyperpolarization by opening the chloride $\left(\mathrm{Cl}^{-}\right)$ channel $(18-20)$, and is considered to be a key role for regulating the activity of HPA. It was reported that more than a third of neurotransmitter inputs to the hypothalamus paraventricle nucleus (PVN) was from GABAergic neurons $(21,22)$. Meanwhile, it was also demonstrated that GABA is a dominant neurotransmitter within the hypothalamus (23). Consistant with the anatomical data mentioned above, there have also been a great number of reports about inhibited corticosterone response to stress induced by the administration of some GABA receptor agonists $(13,19,24)$ and the enhanced $\mathrm{CRH}$ release induced by $\mathrm{GABA}_{\mathrm{A}}$ receptor antagonists (25).

From the view of the increment of GABA in the brain after 1-wk administration of $s$-limonene, it was considered that GABA played a vital role in this anti-stress process. The results demonstrated this suggestion. Flumazenil, as a kind of $\mathrm{GABA}_{\mathrm{A}}$ receptor BZP site antagonist, was used to explore this effect. Flumazenil would attenuate the opening frequency of the $\mathrm{Cl}^{-}$channel which was enhanced by the combination of GABA and intra benzodiazepine. In this study, the increased GABA contents in brain might enhance the combination of this complex, increase the opening frequency and then attenuate the response to stress. When flumazenil, as a type of $\mathrm{GABA}_{\mathrm{A}}$ receptor benzodiazepine site antagonist, was used in the foot-shock experiment with s-limonene, the enhanced combination was attenuated and then the attenuated corticosterone concentration in serum induced by $s$-limonene was reversed. It is therefore suggested that increased GABA contents induced by the administration of $s$-limonene might mediate the antistress effect. However, because the effect of $s$-limonene on the benzodiazepine site was not investigated, the possibility of the effect acting directly through $\mathrm{GABA}_{\mathrm{A}}$ receptor subunits should not be excluded.

It was reported that the activation of the $5-\mathrm{HT}_{1 \mathrm{~A}}$ receptor would enhance HPA activity on the 2nd day (26). A 5-HT-releasing agent, fenfluramine (27), would stimulate ACTH release. It means that 5-HT is one of the facilitation factors for the activation of the HPA axis. The suppression of 5-HT concentration might help to attenuate the responses of the HPA axis to stress. Meanwhile, GABA, as one of the widely distributed neurotransmitters in the brain, regulates the activities of GABAergic neurons or other kinds of neurons; for example, it was reported that GABAergic neurons regulated the activity of 5-HTergic neurons in the dorsal raphe nucleus (DR) $(28-30)$. Since DR is projected to many brain regions, such as the hypothalamus, hippocampus, and amygdala, the declined 5-HT concentration after administration of $s$-limonene could be attributed to $s$-limonene administration increasing GABA content in the brain. The increment of 5-HT after administration of flumazenil confirmed this suggestion. It was also thought that the increased GABA contents induced the decrease of 5-HT under no-stress conditions.

In conclusion, this study has shown that, after 1-wk administration of $s$-limonene, GABA contents in the brain increased significantly, while the glutamate concentration decreased significantly. These changes did not affect the basal activity of HPA, but when rats were given an acute stress, foot shock, $s$-limonene showed a strong ability to attenuate the stress responses. The increased corticosterone contents in serum and 5-HT contents in brains declined. This process may be mediated through the $\mathrm{GABA}_{\mathrm{A}}$ receptor; however, the reason why GABA content was enhanced after $s$-limonene administration is still unclear. This will be explored in further studies.

\section{REFERENCES}

1) Fukumoto S, Morishita, A, Furutachi K, Terashima T. Nakayama T, Yokogoshi H. 2008. Effect of flavour components in lemon essential oil on physical or psychological stress. Stress Health 24: 3-12.

2) Ishikawa S, Miyake Y, Yokogoshi H. 2002. Effect of lemon odor on brain neurotransmitters in rat and electroencephalogram in human subjects. Aroma Research 3: $126-130$.

3) Ceccarelli I, Masi F, Fiorenzani P, Aloisi AM. 2002. Sex differences in the citrus lemon essential oil-induced increase of hippocampal acetylcholine release in rats exposed to a persistent painful stimulation. Neurosci Lett 330: $25-28$.

4) Okuyama S, Terashima T, Kawamura Y, Yokogoshi H. 2004. Enhancing effect of Mycoleptodonoides aitchisonii on synthesis of nerve growth factor and releasing dopamine in the rat brain. Nutr Neurosci 7: 41-47.

5) Yamada T, Nishimura Y, Sakurai T, Terashima T, Okubo T, Juneja LR, Yokogoshi H. 2008. Administration of theanine, a unique amino acid in tea leaves, changed feeding-relating components in serum and feeding behavior in rats. Biosci Biotechnol Biochem 72: 13521355.

6) Poleszak E. 2008. Benzodiazepine/GABA(A) receptors are involved in magnesium-induced anxiolytic-like behavior in mice. Pharmacol Rep 60: 483-489. 
7) Reddy DS, Kulkarni SK. 1996. Role of GABA-A and mitochondrial diazepam binding inhibitor receptors in the anti-stress activity of neurosteroids in mice. Psychopharmacology (Berl) 128: 280-292.

8) Dunn JA. 1988. Stress-related changes in cerebral catecholamine and indoleamine metabolism: lack of effect of adrenalectomy and corticosterone. J Neurochem 51: 406-412.

9) Bradely BF, Starky NJ, Brown SL, Lea RW. 2007. Anxiolytic effects of Lavandula angustifolia odour on the Mongolian gerbil elevated plus maze. J Ethnopharmacol 111: 517-525.

10) Tewtrakul S, Subhadhirasakul S. 2007. Anti-allergic activity of some selected plants in Zingiberaceae family. J Ethnopharmacol 109: 535-538.

11) Shen J, Niijima A, Tanida M, Horii Y, Maeda K, Nagai K. 2005. Olfactory stimulation with scent of grapefruit oil affects autonomic nerves, lipolysis and appetite in rats. Neurosci Lett 380: 289-294.

12) Tanida M, Niijima $A$, Shen J, Nakamura T, Nagai $K$. 2006. Olfactory stimulation with scent of lavender oil affects autonomic neurotransmission and blood pressure in rats. Neurosci Lett 398: 155-160.

13) Cullinan WE. 1998. Evidence for a PVN site of action for gamma aminobutyric acid in the regulatory control of the rat stress axis. Physiologist 41: 379.

14) Durand D, Pampillo M, Caruso C, Lasaga M. 2008. Role of metabotropic glutamate receptors in the control of neuroendocrine function. Neuropharmacology 55: $577-$ 583.

15) Sapher D, Welch JE. 1995. Effects of the serotonin 1 A agonist, 8-hydroxy-2-(di-n-propylamino)tetralin on neurochemical responses to stress. J Neurochem 64: 767-776.

16) Kirby LG, Chou-Green JM, Davis K, Lucki I. 1997. The effects of different stressors on extracellular 5-hydroxytryptamine and 5-hydroxyindoleacetic acid. Brain Res 760: $218-230$.

17) Inoue T, Tsuchiya K, Koyama T. 1994. Regional changes in dopamine and serotonin activation with various intensity of physical and psychological stress in the rat brain. Pharmacol Biochem Behav 49: 911-920.

18) Anuradha H, Srikumar BN, Rao BSS, Lakshmana M. 2008. Euphorbia hirta reverses chornic stress-induced anxiety and mediates its action through the $\mathrm{GABA}_{A}$ receptor benzodiazepine receptor- $\mathrm{Cl}^{-}$channel complex. J Neural Transm 115: 35-42.

19) Jacobson LH, Cryan JF. 2008. Evaluation of the anxi- olytic-like profile of the $G A B A_{B}$ receptor positive modulator CGP7930 in rodents. Neuropharmacology 54: 854-862.

20) Locchi F, Dall'Olio R, Gandolfi O, Rimondini R. 2008. Olanzapine counteracts stress-induced anxiety-like behavior in rats. Neurosci Lett 438: 146-149.

21) Bartanusz V, Muller D, Gaillard RC, Streit P, Vutskits L, Kiss JZ. 2004. Local $\gamma$-aminobutyric acid and glutamate circuit control of hypophyseotrophic corticotrophinreleasing factor neuron activity in the paraventricular nucleus of the hypothalamus. Eur J Neurosci 19: 777782 .

22) Miklos IH, Kovacs KJ. 2002. GABAergic innervation of corticotrophin-releasing hormone (CRH)-secreting parvocellular neurons and its plasticity as demonstrated by quantitative immunoelectron microscopy. Neuroscience 113: 581-592.

23) Decavel C, Van Den Pol AN. 1992. Converging GABAand glutamate-immuno-reactive axons make synaptic contact with identified hypothalamic neurosecretory neurons. J Comp Neurol 316: 104-116.

24) Adachi N, Tomonaga S, Tachibana T, Denbow MD, Furuse M. 2006. (-)-Epigallocatechi gallate attenuates acute stress responses through GABAergic system in the brain. Eur J Pharm 531: 171-175.

25) Tringali G, Aubry MJ, Moscianese K, Zamori C, Vairano M, Preziosi P, Navarra P, Pozzoli G. 2004. Valproic acid inhibits corticotrophin-releasing factor synthesis and release from the rat hypothalamus in vitro: evidence for the involvement of GABAergic neurotransmission. $J$ Psychiatry Neurosci 29: 459-466.

26) Cassano WJ Jr, D'mello AP. 2001. Acute stress-induced facilitation of the hypothalamic-pituitary-adrenal axis: Evidence for the roles of stressor duration and serotonin. Neuroendocrinology 74: 167-177.

27) Dinan TG. 1996. Serotonin and the regulation of hypothalamic-pituitary-adrenal axis function. Life Sci 58: 1683-1694.

28) Jolas T, Aghajanian GK. 1997. Opioids suppress spontaneous and NMDA-induced inhibitory postsynaptic potential in the dorsal raphe nucleus of the rat in vitro. Brain Res 755: 229-245.

29) Pan ZZ, Williams JT. 1989. GABA- and glutamate-mediated synaptic potentials in rat dorsal raphe neurons in vitro. J Neurophysiol 61: 719-726.

30) Roche M, Commons KG, Peoples A, Valentino RJ. 2003. Circuitry underlying regulation of the serotonergic system by swim stress. J Neurosci 23: 970-977. 